\title{
Le dosage des acides gras érythrocytaires: comparaison entre une population de référence et des sujets ayant présenté un infarctus aigu du myocarde.
}

\author{
Le Goff C.1, Leroy L.1,Kaux J.-F.2, Cavalier E.1, Chapelle J.-P.1 \\ 1.Département de Biologie Clinique, Chimie Médicale, CHU de Liège, Belgique \\ 2. Département des Sciences Cliniques, Université de Liège, Belgique
}

\section{Introduction}

Un acide gras (AG) est un acide carboxylique avec une longue chaine aliphatique, qui peut être saturé ou insaturé. Récemment, le rôle des $A G$, particulièrement, celui des oméga-3 et oméga-6, a émergé comme facteur de risque cardiovasculaire dans la littérature. Le but de ce travail était de comparer les taux d'AG mesurés dans une population saine avec ceux obtenus chez des patients admis aux urgences pour un infarctus du myocarde.

\section{Matériels et méthodes}

Cinquante quatre sujets sains ( $33 \pm 11$ ans, 31 femmes) ont été sélectionnés comme population de référence. Ces derniers ont été sélectionnés selon leur mode de vie (alimentation, tabac, etc). En parallèle, nous avons dosé les AG chez 33 patients (55 \pm 9 ans, 12 femmes) admis dans le service d'urgence de notre institution pour infarctus aigu du myocarde (AMI). Le sang était prélevé sur EDTA. Avant l'analyse, les échantillons étaient lavés et transméthylés. Le dosage des AG était réalisé par chromatographie gazeuse couplée à un détecteur à ionisation de flamme (GCFID). Après le dosage, nous avons réalisés une comparaison des taux, sommes et rapport entre les différents AG ainsi que l'index oméga-3 (somme de l'acide eicosapentaénoïque et docosahexaénoïque) obtenus dans les 2 groupes.

\section{Exemple de chromatogramme chez un patient AMI}

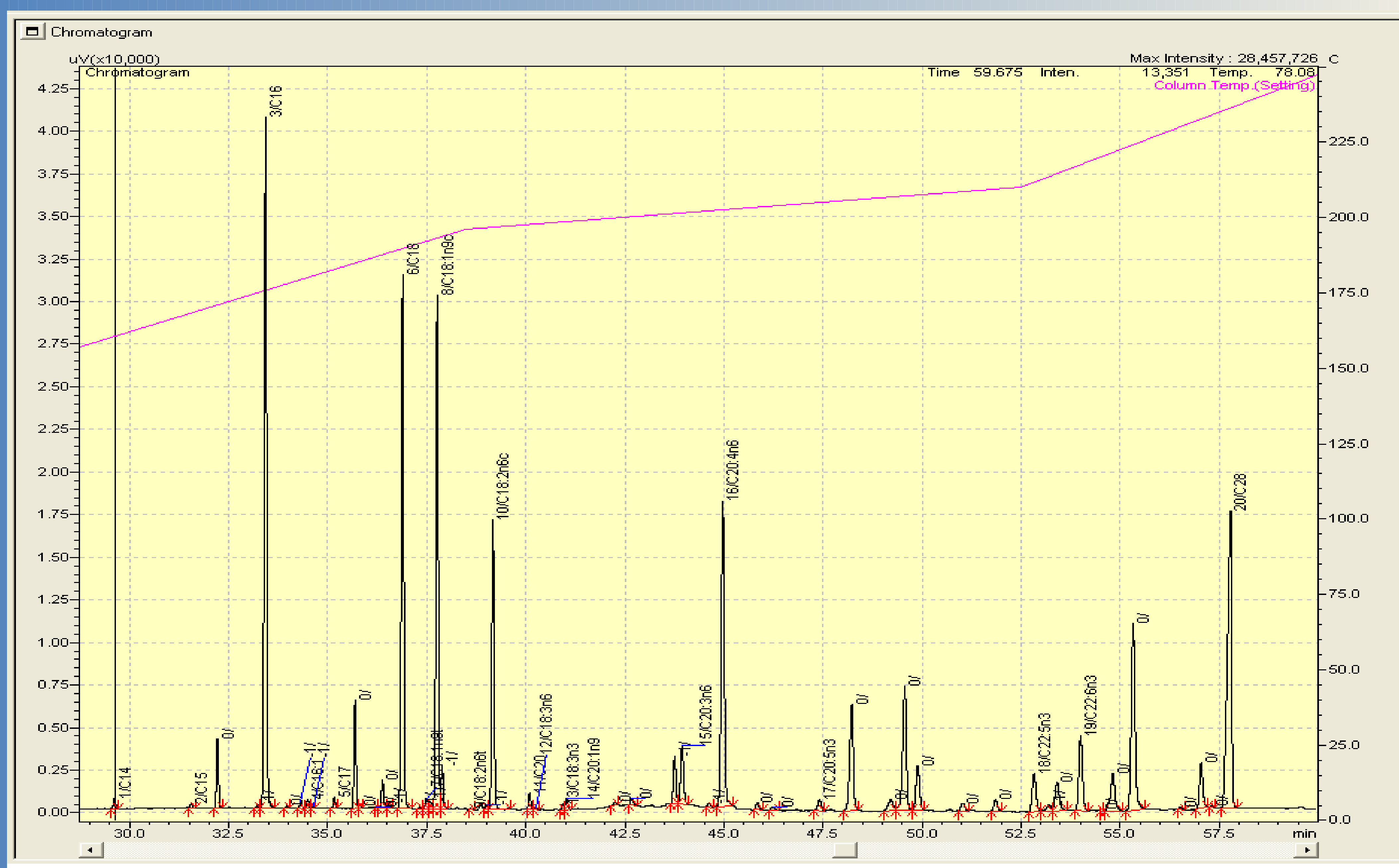

\section{Résultats}

Des valeurs de référence ont été obtenues pour notre population de référence via le logiciel de statistique MedCalc. Dans le groupe AMI, les taux d'oméga-6 étaient significativement plus élevés $(p<0.05)$ pour $\mathrm{C} 18: 2 \mathrm{n} 6$ (Figure 1 ) et $\mathrm{C} 18: 3 \mathrm{n} 6$ (Figure 2)comparés aux résultats obtenus dans la population de référence. Par contre les taux d'oméga-3 étaient significativement plus bas $(p<0.01)$ par rapport aux sujets de référence pour le C22 :6n3 (Figure 3). L'index oméga-3 montrait une valeur plus basse et le rapport oméga-6/oméga-3 était plus élevé dans le groupe AMI comparé aux sujets de référence.
Fig. 1

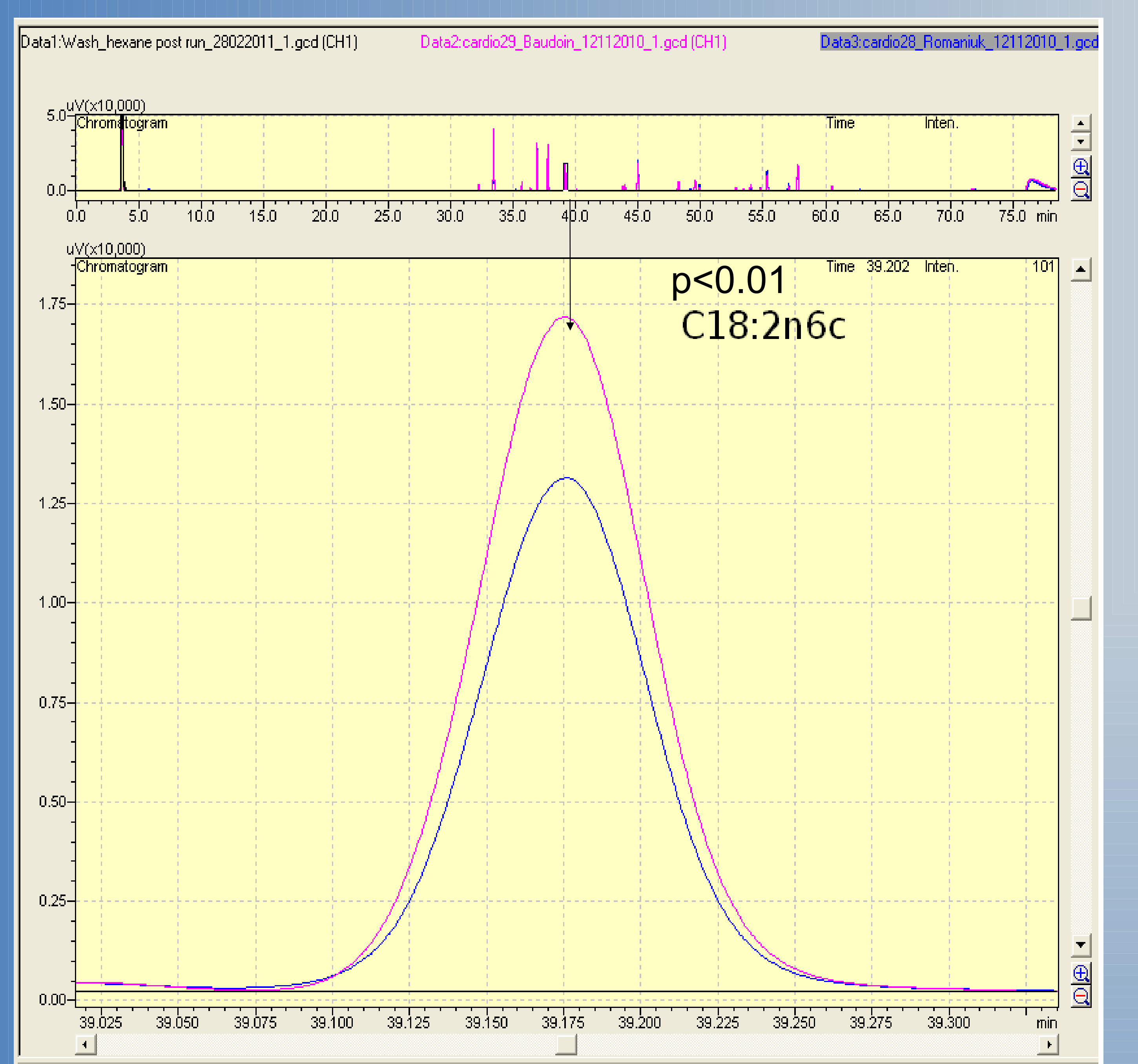

Fig. 2

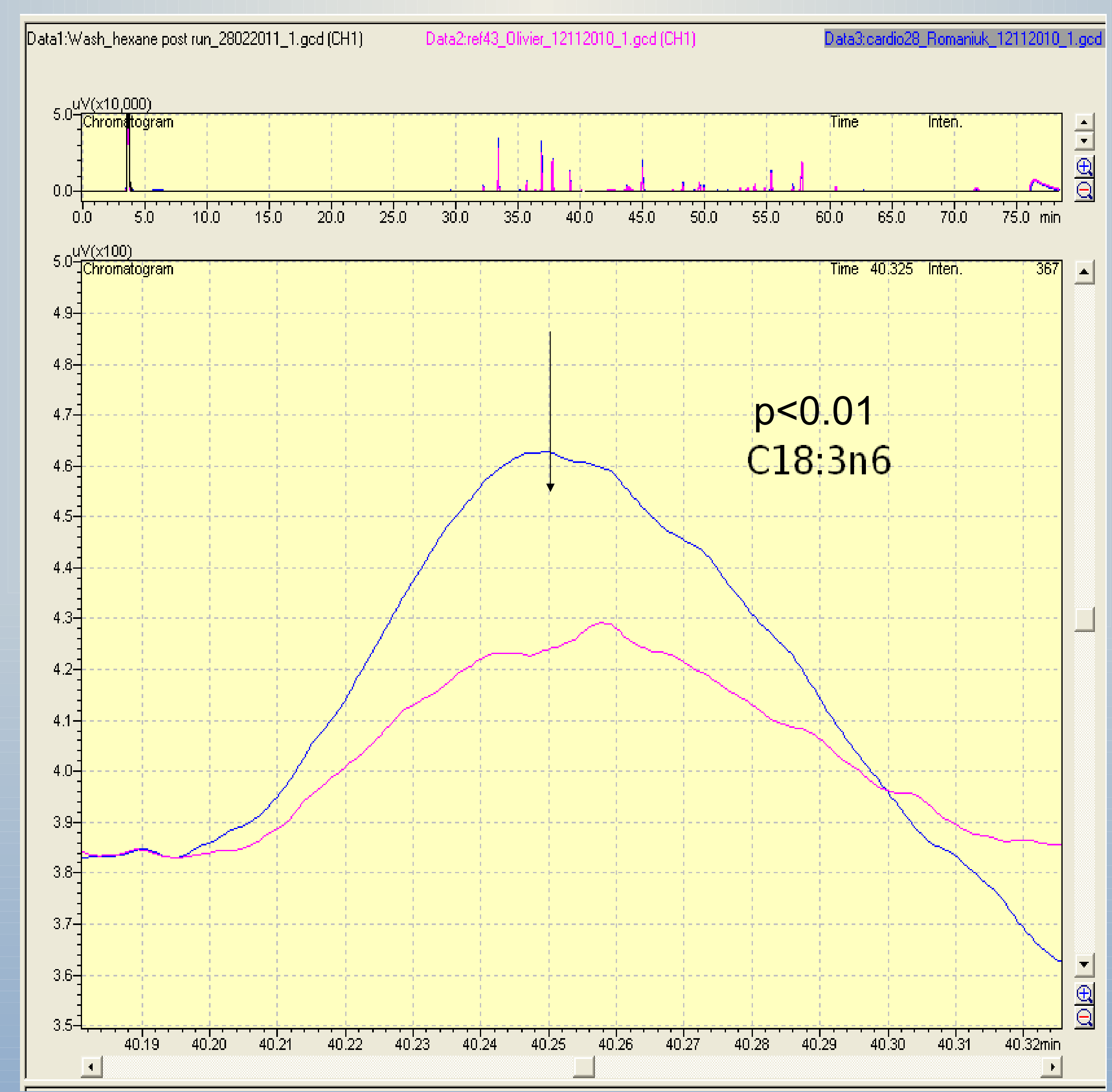

Fig. 3

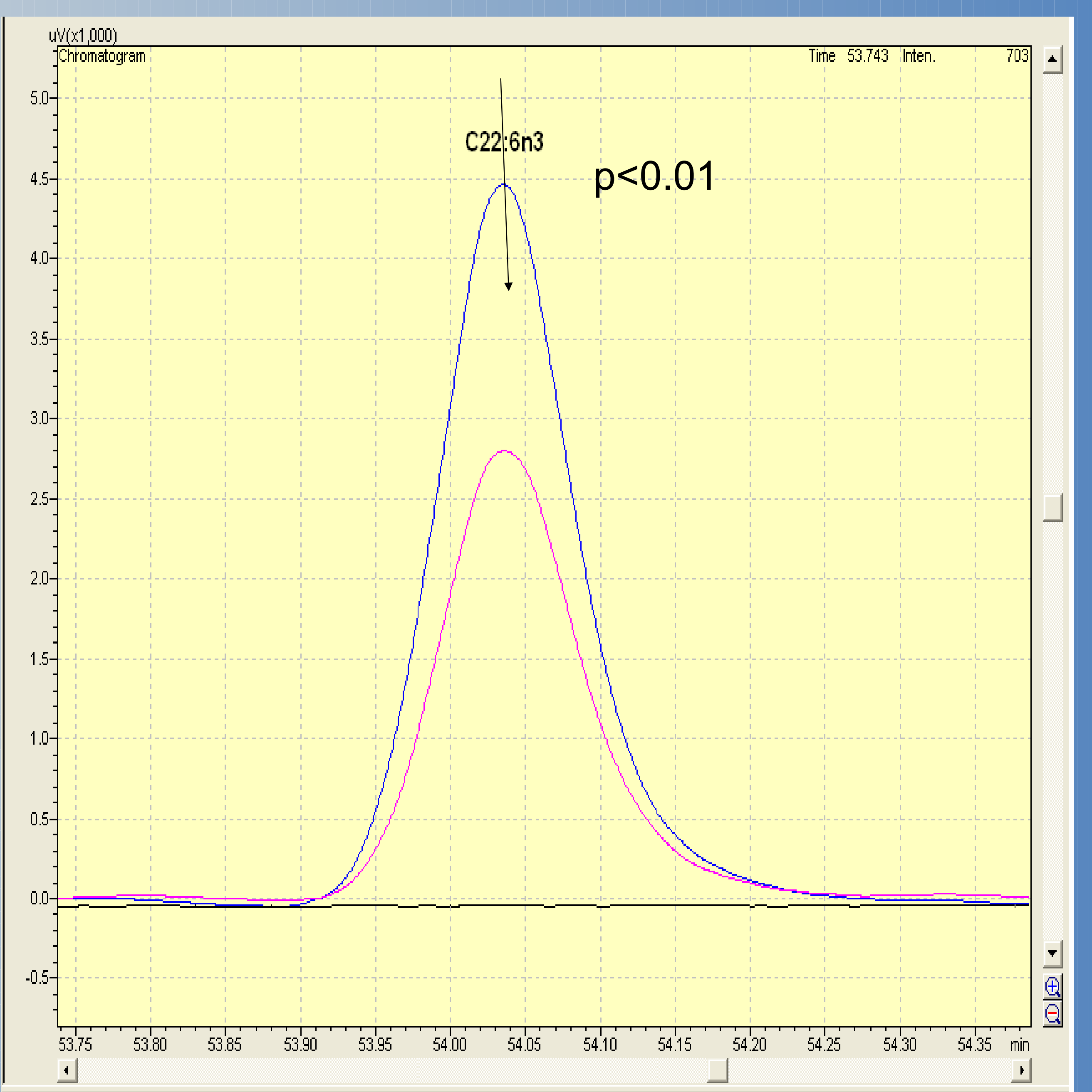

\section{Conclusion}

Le dosage des AG est un nouvel outil que le laboratoire peut proposer aux cliniciens afin de stratifier les patients présentant le plus de risque cardiovasculaire avant ou après un infarctus du myocarde. Ces patients pourraient ainsi être supplémenté en acides gras oméga-3 afin d'éviter les récidives d'infarctus du myocarde ou de diminuer la formation de la plaque d'athérosclérose avant le premier accident. 